7. Reprod. Fert. (1968) 16, 137-139

\title{
THE EVERY-OTHER-DAY PILL
}

\author{
ELSIMAR METZKER GOUTINHO AND JOSÉ GARLOS DE SOUZA \\ Department of Obstetrics (Maternidade Climério de Oliveira) \\ and Biochemistry, University of Bahia, Bahia, Brazil
}

(Received 27th December 1967)

Norgestrel (DL-13 $\beta$-ethyl-17 $\alpha$-ethinyl-17 $\beta$ hydroxy-gon-4-en-3-one) is a potent progestin obtained by total synthesis from non-steroidal precursors (Edgren, Smith, Peterson \& Carter, 1963) which has been proved successful as an oral contraceptive (Coutinho \& de Souza, 1966). Results of experiments assessing the effectiveness of this compound indicated that the recommended daily dose of $0.5 \mathrm{mg}$ norgestrel plus $0.05 \mathrm{mg}$ ethinyl oestradiol was well in excess of the dose necessary to prevent conception, as the missing of one or even two pills never resulted in pregnancy (Coutinho \& de Souza, 1966). As each dose of the combination was apparently effective for at least $48 \mathrm{hr}$ we decided to investigate its contraceptive capabilities when administered on alternate days only.

The new regimen was tested on fifty-one young women of proven fertility and active sexual life for periods ranging from 4 to 12 months. A total of 235 cycles was studied in this series. The menstrual pattern of the patients was noted before the treatment was initiated. Twelve patients had previously experienced irregular cycles and the rest had had regular cycles averaging 27 days. The average duration of the menstrual periods was 5 days (range 3 to 8 ). The patients were divided into four groups according to their menstrual flow, as follows:

$\begin{array}{lr}\text { Normal } & 34 \text { patients } \\ \text { Above normal } & 13 \text { patients } \\ \text { Below normal } & 2 \text { patients } \\ \text { Variable } & 2 \text { patients }\end{array}$

Appropriate examinations were carried out on all patients before and during the treatment. The various complaints of the patients before treatment were thoroughly investigated so as to eliminate possible confusion with any side effects of the drug. The patients were given a month's supply of ten pills and were instructed to take one pill every other day starting on Day 5 of the menstrual cycle. No pregnancies occurred during the treatment but the usual changes resulting from all oral contraceptives were noted in the menstrual pattern of patients.

The menstrual flow lasted for 3 to 8 days in $89 \%$ of the cycles and the quantity was considered normal in $78.4 \%$ of the cycles. Withdrawal bleeding occurred 3 to 7 days after the last pill. The most important side effects were amenorrhoea $(12.7 \%)$ and breakthrough bleeding which occurred in seventy-three cycles $(35.6 \%)$. The latter complication was eliminated by administering an additional pill every other day or by administering a pill daily for 4 consecutive days. 
The menstrual pattern of the patients under treatment is shown in Table 1. Headaches occurred in only $6.8 \%$ and nausea in $3.8 \%$ of all cycles. These and other minor complaints are listed in Table 2. During a period of 6 months nineteen patients gained from 2.2 to $4.4 \mathrm{lb}$ in weight and eight patients lost from 2.2 to $4.4 \mathrm{lb}$. Changes in weight of the remaining patients involved under $2 \cdot 2 \mathrm{lb}$.

\section{TABLE 1}

MENSTRUAL PATTERN OF THE PATIENTS

\begin{tabular}{l|c|c}
\hline & No. of cycles & $\%$ of total \\
\hline Length of cycle (days) & & \\
24 to 33 & 121 & $51 \cdot 4$ \\
Less than 24 & 54 & 22.9 \\
Over 33 & 30 & $12 \cdot 7$ \\
Amenorrhoea & 30 & $12 \cdot 7$ \\
Duration of menstrual flow (days) & & \\
3 to 8 & 220 & $89 \cdot 0$ \\
Less than 3 & 6 & $2 \cdot 5$ \\
Over 8 & 20 & $8 \cdot 5$ \\
Quantity of flow & & \\
Normal & 184 & $78 \cdot 4$ \\
Diminished & 43 & $18 \cdot 2$ \\
Increased & 8 & $3 \cdot 4$ \\
\hline
\end{tabular}

It was concluded that the contraceptive effectiveness of the combination of $0.5 \mathrm{mg}$ norgestrel and $0.05 \mathrm{mg}$ ethinyl oestradiol is unaltered by extending the interval of administration to alternate days. The side effects are less than when the pill is taken during the usual period of 21 days, with the exception of breakthrough bleeding which is easily controllable (see above).

TABle 2

\begin{tabular}{l|c|c}
\multicolumn{2}{c}{ COMPLAINTS DURING TREATMENT } \\
\hline \multicolumn{1}{c|}{ Complaint } & Cycles & $\%$ \\
\hline Headache & 16 & $6 \cdot 8$ \\
Nausea & 9 & $3 \cdot 8$ \\
Abdominal pains & 9 & $3 \cdot 8$ \\
Nervous tension & 8 & $3 \cdot 4$ \\
Dizziness & 8 & $3 \cdot 4$ \\
Loss of balance & 7 & $2 \cdot 9$ \\
Dyspnoea & 5 & $2 \cdot 1$ \\
Pruritus vulvae & 5 & $2 \cdot 1$ \\
Dysuria & 4 & $1 \cdot 7$ \\
Leucorrhoea & 4 & $1 \cdot 7$ \\
Dyspepsia & 4 & $1 \cdot 7$ \\
Backache & 3 & $1 \cdot 2$ \\
Diarrhoea & 3 & $1 \cdot 2$ \\
& & \\
\hline
\end{tabular}

This regimen may be considered a step in the direction of the one-pill-amonth contraceptive proposed by Greenblatt (1967) which, due to its high incidence of side effects, cannot yet be recommended for general use. Although the authors consider the best form of contraceptive regimen to be that using 
the long-acting injectables (Coutinho \& de Souza, 1968) they feel that the everyother-day pill will appeal to those who prefer oral contraception and it offers the distinct advantages of lower dosage, spaced intake and reduced cost.

This work was supported by the Ford Foundation.

\section{REFERENCES}

Coutrnho, E. M. \& de SouzA, J. C. (1966) Controle da fertilidade com um novo progestinico obtido por sintese total. Revta Ginec, obstet., Rio de 7. 118, 374.

Coutinho, E. M. \& DE SouzA, J. C. (1968) Conception control by monthly injections of medroxyprogesterone suspension and a long-acting oestrogen. F. Reprod. Fert. 15, 209.

Edgren, R. A., Smith, H., Peterson, D. L. \& Carter, D. L. (1963) The biological effects of a series of 13-substituted gonanes related to norethisterone (17-alpha-ethinyl-19-nortestosterone). Steroids, 2, 319.

Greenblatt, R. B. (1967) One-pill-a-month contraceptive. Fert. Sieril. 18, 207. 